REVISTA DE DERECHO UNED, NÚM. 14, 2014

\title{
«EL JUICIO DE RESIDENCIA ESPAÑOL, ANTECEDENTE DEL JUICIO DE RESPONSABILIDAD Y NO DEL JUICIO DE AMPARO MEXICANO»
}

\author{
«THE TRIAL OF SPANISH RESIDENCE, BACKGROUND THE \\ TRIAL OF LIABILITY AND NOT THE TRIAL MEXICAN AMPARO» \\ Odilisa GutiérRez Mendoza \\ Doctorando de la UNED \\ odilisagtz@hotmail.com \\ Magistrada de Tribunal Superior Agrario en México
}

\begin{abstract}
Resumen: En el sistema jurídico mexicano, específicamente en lo referente a las responsabilidades de los servidores públicos, la influencia del derecho español es claro; siendo su antecedente el juicio de residencia, que tenía como función principal sancionar a los funcionarios que ocupaban un cargo público en las tierras conquistadas y que se desempeñaban en contravención a las disposiciones emitidas por la corona española. El objetivo principal era la sanción a los servidores por el mal desempeño de las funciones encomendadas. En el juicio de responsabilidad de los servidores públicos en México, la finalidad es la misma que el de residencia española, incluso con sanciones similares a las de este último, las cuales son desde la amonestación hasta la inhabilitación para ocupar un cargo público. Mucho se ha comentado con relación a que el juicio de residencia español, es el antecedente del juicio de amparo mexicano, sin embargo no lo considero así, pues el juicio de amparo tiene como objetivo principal el resarcir a los individuos en la violación de sus derechos humanos cuando alguna autoridad los ha vulnerado, es decir el juicio de amparo gira en la protección del individuo, mientras que el juicio de residencia gira en torno a la evaluación del desempeño del funcionario,
\end{abstract}


pues está dirigido a sancionarlo por su mal desempeño; de ahí que considero no exista relación directa entre ambos procedimientos.

Palabras clave: Residencia, responsabilidad, amparo, español, México.

Abstract: In the mexican legal system, specifically regarding the responsabilities of government employees, the influence of the Spanish law is clear, being it's precedent the residence trial, which main function was to punish officers who held public office in conquered lands and violated dispositions issued by the Spanish crown. The main objective was to punish public officers for their poor fulfillment of the assigned functions. The Mexican liability of public officers trial has the same purpose as the Spanish residence trial, it even has similar sanctions which can go from admonitions to becoming ineligible for public office. Much has been said regarding the fact that the Mexican amparo trial (protection of civil liberties) finds its precedents on the Spanish residence trial, however I must disagree, mainly because the amparo's trial main objective is to compensate the individuals for suffering violations to their human rights by any authority, in other words the amparo trial is mainly about the individual's protection, while the residence trial focuses on the performance evaluation of the officers, for it aims to sanction the officers for their performance; therefore I do not consider there is a direct relation between both procedures.

Keywords: Residence, responsibility, amparo, Spanish, Mexico.

Recepción original: 14/02/2014

Aceptación original: 28/03/2014

Sumario: Introducción; I. El juicio de residencia; I.1 Antecedentes; I.2 Autoridades sujetas al juico de residencia; I.3 Características y procedimiento; II. El juicio de responsabilidad de los servidores públicos en México. II.1 Responsabilidad en el México independiente. II.2 Ley Orgánica del Poder Judicial de la Federación. II.3 Ley Federal de Responsabilidad de los Servidores Públicos. III. Ley de Amparo, reglamentaria de los artículos 103 y 107 de la Constitución Política de los Estados Unidos Mexicanos. III.1 Antecedentes del Amparo mexicano. IV. Conclusiones.

\section{INTRODUCCIÓN}

Es indiscutible la influencia que tuvieron algunas instituciones jurídicas y procedimientos de España en el derecho Mexicano, pues hasta antes de la independencia de México, éste formaba parte de las 
tierras conquistadas por España, y por lo tanto regían las leyes de este lugar. Una de las figuras jurídicas cuyo origen es español, sin duda es la responsabilidad de los servidores públicos, que fue conocida con el nombre de juicio de residencia y que tenía como fin, sancionar a los servidores públicos que se encontraban protegidos con la investidura del estado por el desempeño de sus funciones, institución que prevalece en México tanto para funcionarios de primer nivel como son el presidente de la República, los senadores, diputados, ministros, gobernadores, magistrados, así como servidores públicos de menor rango que desempeñen inadecuadamente sus funciones, los cuales son sancionados a través de diversos procedimientos como veremos en este trabajo. No considero que se deba tomar en cuenta que el juicio de residencia sea el antecedente del juicio de amparo, pues este último no es para sancionar a la autoridad política por el mal desempeño de sus funciones, sino que tiene como finalidad salvaguardar que al gobernado, le sean respetadas cabalmente por la autoridad, las garantías que como ser humano le son intrínsecas.

\section{EL JUICIO DE RESIDENCIA}

\section{I.1. Antecedentes}

El juicio de residencia es el antecedente del juicio de responsabilidad de México, tuvo su origen en el derecho castellano e indiano, su objetivo principal era fiscalizar el desempeño de los funcionarios públicos una vez que abandonaban sus cargos, estos juicios se llevaron a cabo tanto en España como de las posesiones españolas a ultramar considerando la distancia que existía con las tierras conquistadas. De ahí que existía la necesidad de cerciorarse que los funcionarios españoles (virreyes, gobernadores, alcaldes, alguaciles, etc.) cumplieran cabalmente las disposiciones administrativas, políticas y legales, que ordenaba la Corona Española.

Por los años de 1480, en las Cortes de Toledo, se ordenó que los funcionarios hicieran residencia por treinta días, señalando que si al concluir su encargo no otorgaban fianza suficiente para garantizar los posibles daños a que pudieran ser condenados, se les embargaría el último tercio de su salario, con la finalidad de resarcir al agraviado en el daño ocasionado por el funcionario. ${ }^{1}$

\footnotetext{
${ }^{1}$ Fernández Delgado, Miguel Angel y Soberanes Fernández, José Luis, Antecedentes históricos de la responsabilidad de los servidores públicos en México, México, UNAM, 2002, pág. 8, www.biblio.juridicas.unam.mx/libros/2/907/3.pdf
} 
En 1501 se ordenó la primer residencia en las Indias, al nombrar a Nicolás de Ovando para residenciar a Francisco de Bobadilla, en concordancia con la Ley de Toledo. En la Nueva España, la primera residencia fue la realizada a Hernán Cortés ante Luis Ponce de León.

Las personas sujetas a juicio de residencia por motivo de su encargo hasta antes de 1585, eran designadas desde España, quien también decidía quién sería el juzgador, el cual cambiaba atendiendo a la jerarquía del cargo sujeto a juicio de residencia; por ejemplo a los gobernadores los residenciaba la persona que enviara la Corona o el Consejo de Indias. En el caso de alcaldes y corregidores, la Audiencia designaba a jueces en la Nueva España. Después de 1680, la Ley 4, estableció la facultad exclusiva al Consejo de Indias, de nombrar a los jueces de residencia. En el año 1754, la Orden Real se reservó el nombramiento de jueces de residencia en caso de virreyes, los cuales eran elegidos por la Corona a propuesta del Presidente del Consejo. ${ }^{2}$

Dado los abusos que se originaron por el incumplimiento de las disposiciones relativas a los sujetos sancionados, la Real Cédula de 1799 dividió por rangos a los funcionarios de las Indias en tres categorías: La primera se conformaba por los sujetos a quienes se les debía aplicar la ley sin excepción, como lo eran los virreyes, presidentes de audiencia, gobernadores, políticos y militares, gobernadores intendentes, así como los asesores de los mencionados. En la segunda categoría se les eximía de los juicios de residencia por considerarse que eran cargos fáciles de supervisar por sus superiores, en este grupo se encontraron los alcaldes ordinarios, regidores, escribanos, procuradores y alguaciles. En la tercera categoría se encontraban aquellos funcionarios que no estaban contemplados en las categorías antes mencionadas, y que sí eran sujetos del juicio de residencia.

Inicialmente se nombraba un solo juez, sin embargo dada las distancias al lugar en que se instauraba el juicio, se comenzaron a nombrar tres jueces, quienes sustituían al primero cuando no pudiera atender el procedimiento, y a su vez, el tercero sustituía al segundo cuando se declaraba impedido para conocer; sin embargo comenzó a haber corrupción por los jueces y comenzaron a excusarse del conocimiento para permitir cotos de poder a los segundos y terceros. En México se implementó la posibilidad de excusa, sin embargo si no era probada la razón de la misma, se sancionaba al juzgador, situación que hasta la fecha prevalece para juzgadores de este país ${ }^{3}$.

\footnotetext{
2 Ídem, pág. 16.

${ }^{3}$ Ley Orgánica de los tribunales Agrarios, Artículo 28.- Los magistrados y secretarios de acuerdos no son recusables, pero tienen el deber de excusarse del conocimiento
} 


\section{I.2. Autoridades sujetas al juicio de residencia}

Por regla general en una u otra época, casi todos los funcionarios de Indias (América Latina) fueron sujetos al juicio de residencia aunque fue cambiando conforme a las reglas de cada época, éste procedimiento en la administración indiana fue de gran importancia, y comprendía desde virreyes, presidentes de audiencia y gobernadores, hasta alcaldes y alguaciles.

Todos los virreyes debían pasar su juicio de residencia antes de que tomara posesión del cargo su sucesor, pero en el siglo XVIII estos juicios se realizaban una vez que regresaban a España. En este largo proceso se analizaba el grado de cumplimiento de las instrucciones recibidas en su mandato, por lo que durante seis meses se investigaba el desempeño de su labor, reuniendo numerosa información a través de diferentes testigos.

Otra de las fórmulas empleadas por la Corona para controlar a sus funcionarios, incluido el virrey en su calidad de presidente de la audiencia, era a través de la inspección conocida con el nombre de visita, efectuada por un visitador, nombrado por el rey, quien tenía como función conocer los abusos cometidos por las autoridades y proponer las reformas necesarias. En las visitas a diferencia de la residencia era prohibido entregar a acusado las copias de las declaraciones de los testigos y el nombre de los acusadores. Había visitas ordinarias y extraordinarias. ${ }^{4}$

Toda autoridad que terminaba de ejercer su cargo, debía ser sometida a un juicio de residencia, el cual fue llamado así porque consistía en no moverse físicamente del lugar mientras duraba la investigación relativa a su desempeño. En la cédula real de 21 de enero de 1594, se ordenó que los gobernadores que tuvieran cargos por más del tiempo ordinario (seis años), se les tomaran residencia cada cinco años. La pertenencia al clero no era obstáculo para ser residenciado. A petición de la Real Audiencia de México, el 21 de mayo de 1787, la Cédu-

de los asuntos en que exista alguno de los impedimentos previstos en los términos del artículo anterior, debiendo expresar aquél en que se funden

Cuando el magistrado o secretario no se excuse debiendo hacerlo o se excuse sin causa legitima, cualquiera de las partes puede acudir en queja al Tribunal Superior. Si éste encuentra justificada la queja impondrá la sanción correspondiente...

${ }^{4}$ VIÑAs REY, Carmelo, El régimen jurídico y de responsabilidad en la América Indiana, México, UNAM, segunda edición, págs. 52 y 53, "las visitas extraordinarias eran con el fin de fiscalizar la gestión de virreyes, oidores y demás funcionarios, realizadas por visitadores enviados desde España, para dar razón del desempeño de todos los miembros del gobierno del Nuevo Mundo, tanto civiles como eclesiásticos, de todo lo cual daban noticias al consejo de indias». 
la Real relevó de residenciar a la totalidad de los ministros de las Reales Audiencias de las Indias que fueran promovidos a otras plazas, por considerar que habían sido residenciados varias veces y había quedado acreditado su "calificado honor, integridad y moderación», reservándose la Corona la facultad de decidir a qué funcionarios y en qué casos no los exentaba. Posteriormente se estuvo ante la disyuntiva de determinar, si era necesario residenciar a los muertos y cuáles serían las penas que se les impondrían a sus herederos, lo que se agravó en América por las grandes distancias. Aunque esta práctica se oponía a las leyes de las siete partidas, sí se residenció a algunos difuntos durante el s. XVI y principios del s. XVII. En los casos que no se tratara de fraude a la Real Hacienda, eran «absueltos por ser difuntos». ${ }^{5}$

\section{I.3. Características y procedimiento}

El juicio era sumario y público. Si terminado el procedimiento el resultado era positivo, el enjuiciado podía ascender a cualquier cargo; en cambio, si había cometido errores y/o ilegalidades, podía ser sancionado con una multa, o condenado a restituir lo mal llevado, pudiéndosele desterrar e inhabilitar de por vida al funcionario.

El procedimiento de residencia se dividía en dos partes: la primera se investigaba de oficio la conducta del funcionario que dejaba el cargo, y la segunda se recibían las quejas de las personas que se sentían agraviadas con el comportamiento del enjuiciado. Para iniciar el juicio y darle difusión, se hacía público el inicio del procedimiento a través de edictos y del pregón, por su parte el juez de residencia iniciaba sus investigaciones. Cuando el residenciado había ocupado un

${ }^{5}$ Fernández Delgado, Miguel Ángel y Soberanes Fernández, José Luis, Antecedentes históricos de la responsabilidad de los servidores públicos en México, México, UNAM, pág. 20. Al presentarse la muerte del gobernador Francisco Vanegas, acusado de fraude, y poco tiempo después de dictarse la sentencia condenatoria, Juan de Solórzano Pereira opinó que dicha sentencia se podía ejecutar, lo que llegó a oídos del Consejo de Indias, y después de solicitar la opinión de Felipe III, se expidió la Real Cédula de 17 de abril de 1635, la cual disponía que: «los cargos de tratados y contratos de todos los ministros que sirvieren en plazas de asiento u otros oficios o cargos temporales de paz o guerra, cuentas y administración de nuestra real hacienda y en otra cualquier forma, sin excepción de personas, hayan de pasar y pasen contra sus herederos y fiadores por lo tocante a la pena pecuniaria que se les impusiere por ellos, aunque sean muertos al tiempo de la pronunciación de la sentencia, que en el consejo o por otro tribunal o juez, competente se diere contra los culpados, como hayan estado vivos al tiempo que se le dieron los cargos que es cuando parece, que en semejantes juicios se hace contestación de la causa y se les da luz y lugar para que puedan satisfacer, decir, alegar y probar en su defensa y descargo lo que les convenga» 
cargo que abarcaba varias provincias, los edictos eran realizados en las principales villas y ciudades, situación que impedía estar al juez presente en cada una de ellas, por lo que se valía de comisionados, quienes se encargaban de publicitar edictos y tomar testimonios para integrar el expediente, el cual una vez completado era enviado al juez. En los casos de que se tratase de un gobernador, el juez antes de iniciar el juicio, recababa información de los funcionarios sujetos a residencia que habían sido parte de ese gobierno, con la finalidad de hacer sabedores a los indios y que estuvieran en posibilidad de comparecer a presentar sus quejas.

Posteriormente se abría la etapa secreta, que era la del desahogo de pruebas testimoniales y documentales, con amplias facultades del juzgador para recabar de oficio cualquier documento o testimonio que le pudiera llevar a la verdad del caso, llegando al extremo de que se otorgaba valor a las cartas anónimas, lo que tuvo oposición de algunos tratadistas, sin embargo se siguió realizando de esta manera. Respecto a los testigos se tenía que realizar la calificación de la idoneidad, pues no se admitían aquellas personas que habían sido condenados por el residenciado, situación que prevalece hasta nuestros días en las leyes relativas a la valoración de atestes. El residenciado no se podía retirar del lugar de residencia, pues si lo hacía era declarado confeso de las acusaciones que se le presentaban, salvo que la razón de huir fuera por presión de enemigos poderosos o parcialidad del juez, en cuyo caso se dispensaba huir, siempre y cuando se presentara con sus superiores para ser residenciado. Una vez cerrada la etapa secreta, el juez elaboraba una lista de los cargos y corría traslado al residenciado, para que presentara su defensa; ya integrado el expediente, se remitía al juez de residencia para que emitiera su fallo, y con apelación o sin ella, los autos eran enviados a la Audiencia o al Consejo según correspondiera, para que se verificara la segunda instancia. En principio esa segunda instancia correspondió a España, después a las Audiencias de Indias y posteriormente la revisión competía al Consejo y a las cancillerías americanas, pero el gran trabajo hizo que más tarde se resolvieran los asuntos en definitiva por las Audiencias de los Distritos, con excepción de todas las relativas a gobernadores y miembros de las Audiencias, las que se seguían resolviendo por el Consejo, posteriormente sólo resolvía las que se hubiesen integrado por investigación secreta, y las que obedecían a denuncias y querellas se resolvían en las Audiencias Distritales. El tiempo que duraba el juicio de residencia era inicialmente de treinta días, pero la Real Cédula de 31 de agosto de 1582, estableció que podían durar entre sesenta y noventa días atendiendo a las distancias, 
sin obstáculo alguno para resolverlo antes, pues se tenía al residenciado sin poder cambiar su domicilio. En el año de 1667, cuando se estableció el término de seis meses para la residencia de los virreyes de Perú y Nueva España, pudiendo el juez acortarlos. En el año de 1673 se cambió a cinco meses, sólo para los virreyes de la Nueva España.

Hasta la fecha no se ha aclarado de manera definitiva la diferencia entre visita y residencia, pues se habla indistintamente de «visitar en forma de residencia y residenciar por vía de visita. ${ }^{6}$ Se considera que en ambas figuras existían diferencias fundamentales que permiten considerar que eran procedimientos distintos. ${ }^{7}$

Durante el siglo XIX, continuaron los juicios de residencia a ultramar en los lugares en donde no se había declarado la independencia respecto de las tierras conquistadas por España, en donde incluso el Gobernador General de Ultramar era la persona más poderosa, pues concentraba los poderes y unidad de mando en donde al igual que los virreyes eran Capitanes Generales de sus distritos, Gobernadores de los mismos, y Presidentes de las Audiencias, teniendo tratamiento de «muy poderoso Señor». ${ }^{8}$

${ }^{6}$ Fernández Delgado, Miguel Ángel y Soberanes Fernández, José Luis, Antecedentes históricos de la responsabilidad de los servidores públicos en México, México, UNAM, pág. 19, www.biblio.juridicas.unam.mx/libros/2/907/3.pdf

${ }^{7}$ Cfr. Idem, págs. 31 y 32. citando a Mariluz Urquijo y a Solórzano Pereira, Antecedentes históricos de la responsabilidad de los servidores públicos en México, establecen como diferencias las siguientes: 1) En las visitas podían comenzarse a actuar desde antes de la publicación de los edictos. En las residencias el pregón del edicto marcaba la iniciación del procedimiento. 2) En la generalidad delos casos los funcionarios visitados permanecían en sus puestos mientras que los residenciados debian abandonarlos durante el tiempo del juicio. 3) En las residencias se inquiere sobre un periodo de tiempo anterior al juicio y limitado entre dos fechas: la de iniciación del residenciado en el oficio y la cesación en él. En la visita puede investigarse sobre hechos ocurridos luego de la publicación de los edictos. 4) Los nombres de los testigos eran comunicados al residenciado pero no al visitado. 5) Si la sentencia del consejo de Indias contenían condenas de privación perpetua del oficio o pena corporal, podían ser objeto de suplicación en las residencias pero no en las visitas. 6) Ciertos funcionarios de la administración de Indias estaban exentos de las residencias pero no de las visitas. 7) Por lo general el juez gozaba de menos liberad en las residencias que en las visitas, pero estaba sujeto a un mayor formulismo en el procedimiento. 8) La visita era generalmente-aunque no siempre-despachada para investigar el desempeño de un organismo. La residencia tenía por objeto inquirir lo referente al comportamiento de determinados funcionarios, esta circunstancia no obstaba para que pudieran comenzar a la vez los juicios de varios componentes de un organismo o, lo que era más común, que en un mismo juicio se residenciara a todos los que lo integraron en un determinado espacio, como los que podrían ser a manera de ejemplo, las residencias de un gobernador y de los capítulos que formaron parte del cabildo del lugar en que aquel desempeñó sus funciones durante el término de éstos.

${ }^{8}$ Alvarado Planas, Javier, Control y Responsabilidad en la España del XI, Madrid, Dykinson, 2010, pág. 20. 


\section{EL JUICIO DE RESPONSABILIDAD DE LOS SERVIDORES PÚBLICOS EN MÉXICO}

\section{II.1. Responsabilidad en el México independiente}

Hasta nuestros días, el juicio de residencia español tiene efectos en las leyes mexicanas, pues a través de sus normas se consignan disposiciones legales para sancionar y responsabilizar a los servidores públicos en los diferentes cargos que desempeñan, existiendo obligaciones como por ejemplo de elaborar un acta de entrega recepción en cada cargo que concluyen, y en caso de que se advierta por parte de la autoridad un mal desempeño en las funciones, proceden juicos de diversas índoles como lo son: el juico de responsabilidad para los servidores de la administración pública federal, el juicio político, la declaración de procedencia para los Senadores, Diputados Federales, Ministros de la Suprema Corte de Justicia, Magistrados, Secretarios de Estado; la responsabilidad de los juzgadores cuando violan las disposiciones y limitantes que les establecen las leyes orgánicas, (conocer de asuntos en los que se encuentran impedidos, desempeñarse en cargo que se consideran se contraponen a los intereses del cargo desempañado con anterioridad, entre otros). Es importante destacar que al Presidente de la República sólo se le puede responsabilizar en casos de traición a la patria y delitos graves del orden común. ${ }^{9}$ Lo anterior se encuentra sustentado en las diversas cartas constitutivas del sistema político mexicano, desde la independencia hasta la época actual, en la que se contemplan los presupuestos y procedimientos de responsabilidad de los servidores públicos en las normas jurídicas de distintas jerarquías, como a continuación se narra:

La Constitución Política de la Monarquía Española o de Cádiz, rigió en España y sus colonias, tuvo vigencia en lo que era Nueva Es-

\footnotetext{
${ }^{9}$ http://www.diputados.gob.mx/LeyesBiblio/pdf/1.pdf Constitución Política de los Estados Unidos Mexicanos. Artículo 108. Para los efectos de las responsabilidades a que alude este Título se reputarán como servidores públicos a los representantes de elección popular, a los miembros del Poder Judicial Federal y del Poder Judicial del Distrito Federal, los funcionarios y empleados y, en general, a toda persona que desempeñe un empleo, cargo o comisión de cualquier naturaleza en el Congreso de la Unión, en la Asamblea Legislativa del Distrito Federal o en la Administración Pública Federal o en el Distrito Federal, así como a los servidores públicos de los organismos a los que esta Constitución otorgue autonomía, quienes serán responsables por los actos u omisiones en que incurran en el desempeño de sus respectivas funciones.

El Presidente de la República, durante el tiempo de su encargo, sólo podrá ser acusado por traición a la patria y delitos graves del orden común. Los Gobernadores de los Estados, los Diputados a las Legislaturas Locales, los Magistrados de los Tribunales Superiores de Justicia Locales y, en su caso, los miembros de los Consejos de las Judicaturas Locales, serán responsables por violaciones a esta Constitución y a las leyes federales, así como por el manejo indebido de fondos y recursos federales.
} 
paña durante dos breves periodos: a partir de septiembre de 1812 por un año, y de mayo de 1820 a febrero de 1822 . Este ordenamiento establecía que la soberanía reside esencialmente en la Nación y que a ella pertenece el derecho de establecer sus leyes, así como la igualdad de todos los habitantes del imperio. En lo relativo a la declaración de procedencia y juicio político, refería como facultad de la Corte hacer efectiva la responsabilidad de los secretarios de despacho y demás empleados públicos ${ }^{10}$ prohibiendo que emitieran órdenes en contra de la Constitución o de las leyes, aún por instrucción del Rey; ${ }^{11}$ respecto de los diputados quienes gozaban de fuero por sus opiniones, pero no por los crímenes que cometieran, se facultaba al tribunal de Cortes para que los procesara, también se establecía la imposibilidad de ser demandados por deudas de carácter civil, durante el periodo de desempeño y un mes después. ${ }^{12}$ Esta Constitución establecía que el rey no era sujeto de responsabilidad ${ }^{13}$.

El Decreto de la Constitución de Apatzingán (1814), fue un documento con importantes principios políticos que reflejaban la necesidad de lograr una organización propia y autónoma, en ella se plasmaron los ideales de Morelos en los «Sentimientos de la Nación», donde expuso en 1813, entre otros puntos, que «América es libre e independiente de España y de cualquier otra nación, gobierno o monarquía», y que la soberanía dimanaba esencialmente del pueblo. Morelos conjuntó esfuerzos de diversos grupos, que desde 1810 habían emprendido la guerra por la independencia, y en un Congreso Constituyente Interino se expidió en octubre de 1814, el Decreto Constitucional para la Libertad de la América Mexicana, mejor conocido como Constitución de Apatzingán, sin embargo no pudo entrar en vigor, porque amenazaba los intereses de los españoles, que aún dominaban al país; establecía los derechos humanos de igualdad, seguridad, propiedad y

${ }^{10} \mathrm{http}: / / w w w . c o n g r e s o . e s / d o c u / c o n s t i t u c i o n e s / 1812 / c e 1812 \_c d . p d f$ Constitución de Cádiz. Artículo 25. Hacer efectiva la responsabilidad de los secretarios de despacho y demás empleados públicos.

${ }^{11}$ Ídem. Artículo 226. Los Secretarios de Despacho serán responsables a las Cortes de las órdenes que autoricen contra la Constitución o las leyes, sin que les sirva de excusa haberlos mandado el Rey. Artículo 228. Para hacer efectiva la responsabilidad de los Secretarios del Despacho, decretaran ante todas cosas, las cortes que ha lugar a la formación de causa.

12 Ídem. Artículo 128. Los diputados serán inviolables por sus opiniones y en ningún tiempo ni caso, ni por ninguna autoridad podrán ser reconvenidos por ellas. En las causas criminales, que contra ellos se intentaren, no podrán ser juzgados, sino por el tribunal de Cortes, en el modo y forma que se prescriba en el reglamento del gobierno interior de las mismas. Durante las sesiones de las Cortes y un mes después, los diputados no podrán ser demandados civilmente, ni ejecutados por deudas.

13 Ídem. Constitución de Cádiz. Artículo 168. La persona del Rey es sagrada e inviolable, y no está sujeta a responsabilidad. 
libertad, la religión católica como la única reconocida en el país, así como la división de poderes, tocante al sufragio, instituía juntas electorales de parroquia, de partido y de provincia.

En lo referente a la responsabilidad de los funcionarios, se prohibía a los secretarios emitir órdenes en contra de las disposiciones plasmadas en la Constitución ${ }^{14}$, teniendo facultad el Congreso para inhabilitar al funcionario ${ }^{15}$ y obligado a enviar el expediente al Supremo Tribunal de Justicia quien instauraría el procedimiento y dictaría sentencia $^{16}$.

Tras la consumación de la independencia, se instaló el primer Congreso Constituyente en febrero de 1822, en el cual se proclamó emperador a Agustín de Iturbide. Éste lo disolvió tres meses después, pero ante la posibilidad de ser despojado del trono debido a la inestabilidad política que provocó su autoritarismo, lo reinstaló en marzo de 1823 y ahí se declaró la nulidad de su coronación.

En enero de 1824 un nuevo Congreso estableció el Acta Constitutiva de la Federación, que instituía el sistema federal. Dos meses después inició el debate que llevó la promulgación de la Constitución Federal de los Estados Unidos Mexicanos el 3 de octubre de ese año. Esta Acta Constitutiva estableció la facultad a las cámaras ${ }^{17}$ (diputa-

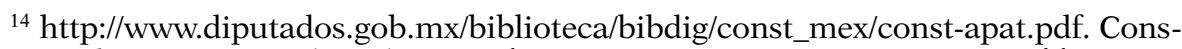
titución de Apatzingán (1814). Artículo 145 Los secretarios serán responsables en su persona de los decretos, órdenes y demás que autoricen contra el tenor de este decreto o contra las leyes que mandadas observar, y que en adelante se promulgaren.

15 Ídem. Constitución de Apatzingán (1814), Artículo 146; Para hacer efectiva esta responsabilidad decretará ante todas cosas el Congreso, con noticia justificada de la trasgresión, que ha lugar a la formación de la causa.

${ }_{16}$ Ídem. Constitución de Apatzingán (1814), Artículo 147; Dado este decreto, quedará suspenso el Secretario, y el Congreso remitirá todos los documentos que hubiere al Supremo Tribunal de Justicia, quien formará la causa, la sustanciará y sentenciará conforme a las leyes.

${ }^{17}$ Ídem. Acta Constitutiva de la Federación (1824) Artículo 38; cualquiera de las dos cámaras podrá conocer en calidad de gran jurado sobre las acusaciones:

I.- Del Presidente de la Federación, por delitos de traición, contra la independencia nacional, o las formas establecidas de gobierno, y por cohecho o soborno, cometidos durante el tiempo de su empleo.

II.- del mismo Presidente por actos dirigidos manifiestamente a impedir que se hagan las elecciones de Presidente, senadores y diputados, o que éstos se presenten a servir sus destinos en las épocas señaladas en ésta Constitución, o a impedir a las cámaras el uso de cualquiera de las facultades que les atribuye la misma.

III.- De los individuos de la Corte Suprema de Justicia y de los Secretarios de Despacho, por cualesquiera delitos cometidos durante el tiempo de sus empleos.

IV.- De los Gobiernos de los Estados por infracción de la Constitución Federal, leyes de la Unión, u órdenes del presidente de la Federación, que no sean manifiestamente contrarias a la Constitución y Leyes generales de la Unión, y también por la publicación 
dos y senadores) para conocer como gran jurado de las acusaciones que se realizaran en contra del Presidente de la Republica (solo en delitos contra el estado o contra la democracia), de los integrantes de la Corte Suprema de Justicia y de los secretarios de estado (por delitos cometidos durante su encargo), a los gobiernos de los estados (cuando actuaran o emitieran decretos en contra de la Constitución y de las leyes). También se estableció los casos en que la cámara de diputados sería constituida como gran jurado, y una vez emitida la resolución la turnaría a Suprema Corte de Justicia (asuntos contra el presidente y sus ministros en los que haya intervenido el senado $)^{18}$.

Las Siete Leyes Constitucionales (1835-1836) con Santa Anna en la presidencia por segunda ocasión, el Congreso de mayoría conservadora centralista, inició la elaboración de las Bases para una nueva Constitución, conocida como Las Siete Leyes, que pondría fin al sistema federal. La primera ley se promulgó el diciembre de 1835, la segunda en abril de 1836 y las restantes en diciembre de ese año. Con este ordenamiento se dividía al país en departamentos, éstos en distritos y los distritos en partidos. Entre otras disposiciones, fijó el periodo presidencial en ocho años y estableció un Supremo Poder Conservador, sólo responsable ante Dios, con atribuciones para declarar nulidad de una ley o decreto, la incapacidad física o moral del presidente de la República, y la clausura del Congreso. ${ }^{19}$. En lo referente a las responsabilidades se plasmó el fuero constitucional para el Presidente de la República, Senadores, Magistrados de la Alta Corte de Justicia y la Marcial, Secretarios y Gobernadores. ${ }^{20}$. En los delitos

de leyes y decretos de las legislaturas de sus respectivos estados, contrarias a la misma Constitución y leyes.

${ }_{18}$ Ídem. Acta Constitutiva de la Federación (1824) Artículo 39. La Cámara de representantes hará exclusivamente de gran jurado, cuando el presidente o sus ministros sean acusados por actos en que hayan intervenido el senado o el consejo de gobierno en razón de sus atribuciones. Esta misma cámara servirá del mismo modo de gran jurado en los casos de acusación contra del vicepresidente, por cualesquiera delitos cometidos durante el tiempo de su destino.

Artículo 40. La cámara ante la que se hubiese hecho la acusación de los individuos de que hablan los dos artículos anteriores, se erigirá en gran jurado, y si declarare por el voto de los dos tercios de sus miembros presentes haber lugar a la formación de causa, quedará el acusado suspenso de su encargo, y puesto a disposición del tribunal competente.

${ }^{19}$ GonzÁlez, Gerardo A., Historia de la Constitución Mexicana, Uruguay, en Contexto, 2001, pág.148.

${ }^{20} \mathrm{http} / / /$ www.ordenjuridico.gob.mx/Constitucion/1836.pdf Siete Leyes. Artículo 47. En los delitos comunes no se podrá intentar acusación criminal contra el Presidente de la República, desde el día de su nombramiento hasta un año después de terminada su presidencia, ni contra los senadores desde el día de su elección hasta que pasen dos meses de terminar su encargo, ni contra los ministros de la alta Corte de Justicia y la Marcial, Secretarios del despacho, consejeros y gobernadores de los Departamentos, sino 
oficiales de los funcionarios mencionados en el párrafo anterior, por la infracción del Artículo 3, parte quinta de la segunda ley constitucional $^{21}$, del 3 de la cuarta ${ }^{22}$ y del 15 de la sexta en sus tres primeras partes $^{23}$, la Cámara de diputados, ante quien debía hacerse la acusación tenía que declarar si era procedente o no, en caso de ser la declaración afirmativa, nombraría a dos de sus miembros para sostener la acusación en el Senado. Éste, instruido el proceso y oídos los acusadores y defensores, tenía que emitir su fallo sin más condena que la destitución del empleado en el cargo, o inhabilitarlos definitiva o temporalmente para obtener otro; pero si del proceso el Senado consideraba que se actualizaban mayores penas, turnaba el expediente al tribunal respectivo para que obrara según sus leyes.

En las Bases Orgánicas de la República Mexicana (1843), época en que México sufre la pérdida del territorio de Texas, aunado a la intención de Yucatán por separarse del territorio Mexicano, así como el descontento social contra el gobierno de Santa Anna, en abril de 1842 se elabora el proyecto de Constitución en el que Mariano Otero propone un gobierno republicano, representativo, popular y federal, así como un sistema de representación de las minorías, lo que ocasionó gran descontento de la fracción conservadora que derivó en diversos enfrentamientos, por lo que el congreso fue disuelto. En junio de 1843 se sancionó una nueva Carta Magna, llamada Bases Orgánicas de la República Mexicana, que sólo estuvieron en vigor tres años, reiteraron la independencia del país, la organización política en República Centralista, y suprimieron al Supremo Poder Conservador que

ante la Cámara de diputados. Si el acusado fuere diputado, en el tiempo de su diputación y dos meses después, o el Congreso estuviere en receso, se hará la acusación ante el Senado.

${ }^{21}$ Ídem. Segunda Ley; Art. 3; frac. V; Las omisiones de la elección el día prefijado y la de envío de la acta de ella, será caso de responsabilidad para la juntas departamentales, según lo que prevenga la ley de la materia

${ }_{22}^{2}$ Ídem, Cuarta Ley; Art. 3.- Los actos especificados en el artículo anterior serán nulos, ejecutándose en otros días que los asignados en él, y solo en caso de que un trastorno social imposibilite o la reunión del congreso, o la mayor parte de las juntas departamentales, el congreso, con el voto de las dos terceras partes de los individuos presentes de cada cámara, designará otro día, valiéndose este acuerdo extraordinariamente y por aquella sola vez.

${ }^{23}$ Ídem. Sexta Ley; Art. 15; Restricción de los gobernadores y juntas departamentales. frac. I.- Ni con el título de árbitros ni con cualquier otro, podrán imponer contribuciones, sino en los términos que expresa esta ley, ni destinarlas a otros objetos que los señalados por las mismas. Frac. II.- No podrán adoptar medidas algunas para levantamiento de fuerzas armadas, sino en los casos que expresamente estén facultados por las leyes para este objeto, o en el que se les ordene por el gobierno general. Frac. III.- No podrán usar de otras facultades que las que les señala esta ley, siendo la contravención a esta parte del artículo y a las dos anteriores casos de la más estrecha responsabilidad. 
encabezaba el propio Santa Anna. Respecto de la responsabilidad de los servidores públicos, se estableció el fuero constitucional para los diputados y senadores por motivo de opiniones, y de los delitos que cometieran civiles o criminales durante su encargo y dos meses después de dejar el mismo, ${ }^{24}$ sin embargo se les otorgó facultad para conocer de la responsabilidad de los delitos cometidos por secretarios de despacho, ministros de la Corte Suprema de Justicia y Marcial, Consejeros de gobierno y Gobernadores de departamento. ${ }^{25}$.

Ante los levantamientos a favor de poner en vigencia nuevamente los ordenamientos constitucionales del federalismo, el 10 de mayo de 1847 en el Congreso Extraordinario Constituyente, se aprobó el Acta Constitutiva y de Reformas, estableciendo el federalismo, de manera formal puesto que la Constitución de 1824 había sustituido a la Constitución centralista conocida como Bases Orgánicas desde agosto de 1846, pero con diversas modificaciones para evitar caer nuevamente en situaciones de conflicto político. Por ejemplo, contemplaba que los poderes Legislativo, Ejecutivo y Judicial «solo pueden y deben hacer lo que la Constitución otorga como facultad e impone como obligación». En cuanto a las responsabilidades estableció la del Presidente por delitos comunes y los oficiales, siempre que no estuviera autorizado por su Secretario ${ }^{26}$, pues de estar autorizado por el último en mención, la responsabilidad sería de este. Los secretarios de despacho eran responsables por actos $\mathrm{u}$ omisiones que infringieran la Ley. ${ }^{27}$

La Constitución Federal (1857) ${ }^{28}$ estuvo marcada por el desconocimiento del gobierno de Santa Anna, convocándose a un Congreso Extraordinario en 1856. En cuanto a la responsabilidad, se plasmó que el Presidente de la República durante su desempeño, sólo podría

${ }^{24}$ http://www.juridicas.unam.mx/infjur/leg/conshist/pdf/1842.pdf 'Bases Orgánicas de la República Mexicana. Artículo 74, Los diputados y senadores no podrán ser juzgados en sus causas criminales y civiles durante su encargo y dos meses después, sino en la forma prevenida por la Constitución y las leyes.

${ }_{25}$ Ídem. Artículo 77. Cualquiera de las dos Cámaras podrá conocer en calidad de gran jurado, para el efecto de declarar si ha o no lugar a la formación de causa, en las acusaciones por delitos oficiales o comunes de los secretarios del despacho, ministros de la Corte Suprema de justicia y marcial, consejeros de gobierno y de los Gobernadores de Departamento.

${ }^{26} \mathrm{http} / / /$ www.ordenjuridico.gob.mx/Constitucion/1847.pdf Acta Constitutiva de Reforma 1847; Artículo 1: El presidente es responsable de los delitos comunes que cometa durante el ejercicio de su encargo, y aun de los de oficio exceptuados por la Constitución, siempre que el acto en el cual consistan, no esté autorizado por la firma del secretario responsable.

${ }^{27}$ Ídem, Artículo 17: Los secretarios del despacho responden de todas las infracciones de ley que cometan, ora consistan en actos de comisión, o sean de pura omisión.

${ }^{28}$ www.juridicas/unam.mx/infjur/leg/conshist/pdf/1857.pdf 
acusársele de traición a la patria, violación a la Constitución, a la libertad electoral y por delitos graves del orden común..$^{29}$ Se estableció también la imposibilidad de indultar al funcionario sancionado por el legislativo en juicio político o declaración de procedencia, así como la desaparición del fuero, respecto de las responsabilidades del orden civil.

La Constitución Política de los Estados Unidos Mexicanos que data de $1917^{30}$ y que se encuentra vigente en nuestro días, con algunas reforma, pero conservando su esencia, establece que el juicio político puede iniciar con la denuncia que presente cualquier ciudadano ante la cámara de diputados por las faltas en que incurran los servidores públicos señalados en el artículo 110 de nuestra Carta Magna, cuando incurran en actos $\mathrm{u}$ omisiones que redunden perjuicio a los intereses públicos fundamentales o de su buen gobierno y presentando los elementos de prueba necesarios para acreditar la falta.

Sus características son las siguientes ${ }^{31}$ : Es un juicio uninstancial, opera el principio de coordinación de las cámaras integrantes del Congreso de la Unión, es un juicio restringido porque se sigue sólo a determinado número de servidores públicos, se refiere a tipos delictivos especiales (por violaciones graves a la Constitución y a las leyes que de ella emanen, así como por el manejo indebido de fondos y recursos federales). El Presidente de la República podrá ser sujeto de responsabilidad durante el desempeño de su encargo únicamente por traición a la patria o por delitos graves del orden común. Sin embargo el único intento por determinar legislativamente los contenidos de estos delitos los elaboró Álvaro Obregón ${ }^{32}$. El procedimiento para enjuiciar al Presidente de la República es especial. La sentencia que se emita en estos procedimientos es inatacable, por lo que en principio no podrá ser impugnada ni siquiera por el juicio de amparo ${ }^{33}$. La declaración de procedencia es un acto político, administrativo, de contenido penal, procesal, irrenunciable, transitorio y revocable, compe-

${ }^{29}$ Ídem. Constitución Federal de 1857. Artículo 103. Los Diputados del Congreso de la Unión, los individuos de la Suprema Corte de Justicia, y los Secretarios de Despacho, son responsables por los delitos, faltas u omisiones en que incurran en el ejercicio de ese mismo encargo..... Lo es también el Presidente de la República; pero durante el tiempo de su encargo solo podrá ser acusado por los delitos de traición a la patria, violación expresa de la Constitución, ataque a la libertad electoral y delitos graves del orden común.

${ }^{30}$ Diario Oficial de la Federación,5 de septiembre de 2013, México.

${ }^{31}$ Arteaga Nava, Elisur, Derecho Constitucional, México, Oxford, Segunda Edición, 2004, págs. 919-923.

32 Tena Ramírez Felipe, Derecho Constitucional, México, Porrúa, 1980, pág.577

${ }_{33}$ González Shmal, Raúl, Programa de Derecho Constitucional, México, Limusa, 2003, págs. 425 y 426. 
tencia de la cámara de diputados que tiene por objeto poner a un servidor público a disposición de las autoridades judiciales, a fin de que sea juzgado exclusivamente por el o los delitos cometidos durante el desempeño de su encargo y que la declaración precisa. Las características del acto que emite la cámara de diputados no es una sentencia sino una determinación ya que el jurado de sentencia no juzga los hechos, ni establece la culpabilidad o inocencia del reo, ni puede imponer pena alguna. La resolución que emite la cámara de diputados ya sea en sentido negativo o positivo, de ninguna manera puede considerarse una sentencia ya que la constitución se encarga de precisar su naturaleza: una resolución declarativa, sin más fuerza que poner al servidor público a disposición del ministerio público o del juez. Este proceso parlamentario es conocido en la práctica como desafuero. Hay que señalar, desde este momento, que tal declaración se desarrolla exclusivamente en la Cámara de Diputados en los siguientes supuestos: Cuando se presente denuncia o querella por particulares o requerimiento del Ministerio Público para el ejercicio de la acción penal. Cuando a juicio de la sección instructora la imputación fuese notoriamente improcedente, lo hará saber de inmediato a la Cámara, para que resuelva si se continúa o desecha, sin perjuicio de reanudar el procedimiento si posteriormente aparecen motivos que lo justifiquen (Art. 25, Ley Federal de Responsabilidad de los Servidores Públicos).

De nueva cuenta podemos afirmar que este procedimiento tiene su origen en el juicio de residencia.

\section{II.2. Ley Orgánica del Poder Judicial de la Federación}

Otra de las leyes que establecen las responsabilidades de los juzgadores y que considero tiene como antecedente el juicio de residencia español es la Ley Orgánica del Poder Judicial de la Federación, sin que en esencia pueda equiparase en su totalidad, pues esta Ley es para sancionar a los juzgadores que han incurrido en faltas durante el desempeño de su función, y no propiamente a los servidores públicos por su mal desempeño, pues aquel era eminentemente político, sin embargo el procedimiento que se lleva a cabo es similar al que se realizaba en las residencias españolas.

Esta ley regula la organización del Poder Judicial de la Federación, los órganos integrantes, su funcionamiento, atribuciones, establece también la integración del Consejo de la Judicatura Federal, la que entre otras funciones destaca la facultad de suspender en sus 
cargos a los magistrados en los casos de responsabilidad penal, ${ }^{34}$ resolver sobre las quejas administrativas por violación al artículo $101^{35}$ de la Constitución Federal. También es facultad de este órgano, realizar visitas de supervisión, con la finalidad de revisar que el juzgado o tribunal se encuentre funcionando adecuadamente y sus integrantes estén conduciéndose conforme a los lineamientos de conducta establecidos. $^{36}$

${ }^{34}$ Diario Oficial de la Federación, 11 de diciembre de 2012, Ley Orgánica del Poder Judicial de la Federación, Artículo 81; Fracciones X. Suspender en sus cargos a los magistrados de circuito y jueces de distrito a solicitud de la autoridad judicial que conozca del procedimiento penal que se siga en su contra. En estos casos, la resolución que se dicte deberá comunicarse a la autoridad que la hubiere solicitado. La suspensión de los magistrados de circuito y jueces de distrito por parte del Consejo de la Judicatura Federal, constituye un requisito previo indispensable para su aprehensión y enjuiciamiento. Si llegare a ordenarse o a efectuarse alguna detención en desacato a lo previsto en este precepto, se procederá en términos de la fracción XIX del artículo 225 del Código Penal. El Consejo de la Judicatura Federal determinará si el juez o magistrado debe continuar percibiendo una remuneración y, en su caso, el monto de ella durante el tiempo en que se encuentre suspendido;...XI. Suspender en sus funciones a los magistrados de circuito y jueces de distrito que aparecieren involucrados en la comisión de un delito, y formular denuncia o querella contra ellos en los casos en que proceda; XII. Resolver sobre las quejas administrativas y sobre la responsabilidad de servidores públicos en términos de lo que dispone esta ley incluyendo aquellas que se refieran a la violación de los impedimentos previstos en el artículo 101 de la Constitución Política de los Estados Unidos Mexicanos por parte de los correspondientes miembros del Poder Judicial de la Federación, salvo los que se refieran a los miembros de la Suprema Corte de Justicia;

${ }^{35}$ Diario Oficial de la Federación, 5 de septiembre de 2013. Constitución Política de los Estados Unidos Mexicanos (2013) Artículo 101.- Los Ministros de la Suprema Corte de Justicia, los Magistrados de Circuito, los Jueces de Distrito, los respectivos secretarios, y los Consejeros de la Judicatura Federal, así como los Magistrados de la Sala Superior del Tribunal Electoral, no podrán, en ningún caso, aceptar ni desempeñar empleo o encargo de la Federación, de los Estados, del Distrito Federal o de particulares, salvo los cargos no remunerados en asociaciones científicas, docentes, literarias o de beneficencia. Las personas que hayan ocupado el cargo de Ministro de la Suprema Corte de Justicia, Magistrado de Circuito, Juez de Distrito o Consejero de la Judicatura Federal, así como Magistrado de la Sala Superior del Tribunal Electoral, no podrán, dentro de los dos años siguientes a la fecha de su retiro, actuar como patronos, abogados o representantes en cualquier proceso ante los órganos del Poder Judicial de la Federación... La infracción a lo previsto en los párrafos anteriores, será sancionada con la pérdida del respectivo cargo dentro del Poder Judicial de la Federación, así como de las prestaciones y beneficios que en lo sucesivo correspondan por el mismo, independientemente de las demás sanciones que las leyes prevean.

${ }^{36}$ Diario Oficial de la Federación. 11 de diciembre de 2012. Ley Orgánica del Poder Judicial de la Federación. Artículo 98. La Visitaduría Judicial es el órgano auxiliar del Consejo de la Judicatura Federal competente para inspeccionar el funcionamiento de los tribunales de circuito y de los juzgados de distrito, y para supervisar las conductas de los integrantes de estos órganos.

ARTículo 100. Los visitadores... deberán inspeccionar de manera ordinaria los tribunales de circuito y juzgados de distrito cuando menos dos veces por año, de conformidad con las disposiciones generales que emita el Consejo de la Judicatura Federal en esta materia 


\section{II.3. Ley Federal de Responsabilidad de los Servidores Públicos}

Sin duda este sistema de responsabilidad, es el antecedente directo de los juicios de residencia que se siguieron en la época de la conquista, y que como ya ha quedado anotado tenían como finalidad principal que los funcionarios fueran supervisados en el desempeño de su encargo, con la facultad de destituirlos, inhabilitarlos e incluso sancionarlos pecuniariamente cuando faltaran a su encomienda.

Esta ley tiene como objetivo al igual que en origen, sancionar a los servidores públicos que refiere el artículo 108 de la constitución, que se transcribe: "Para los efectos de las responsabilidades a que alude este Título se reputarán como servidores públicos a los representantes de elección popular, a los miembros del Poder Judicial Federal y del Poder Judicial del Distrito Federal, los funcionarios y empleados y, en general, a toda persona que desempeñe un empleo, cargo o comisión de cualquier naturaleza en el Congreso de la Unión, en la Asamblea Legislativa del Distrito Federal o en la Administración Pública Federal o en el Distrito Federal, así como a los servidores públicos de los organismos a los que esta Constitución otorgue autonomía, quienes serán responsables por los actos u omisiones en que incurran en el desempeño de sus respectivas funciones.

El Presidente de la República, durante el tiempo de su encargo, sólo podrá ser acusado por traición a la patria y delitos graves del orden común». Además de los anteriores, también son sujetos de responsabilidad bajo la tutela de la ley de responsabilidad de los servidores públicos, las personas que manejen recursos económicos federales. ${ }^{37}$

Como parte del procedimiento del juicio político y la declaración de procedencia a los servidores públicos que menciona el transcrito artículo 108 de la Constitución Política Mexicana, la procedencia de las sanciones será cuando incurran en actos u omisiones que afecten la legalidad, honradez, lealtad, imparcialidad y eficiencia que deben observar en el desempeño del empleo, cargo o comisión, siendo los objetivos principales del juicio de residencia, en el que se sancionaba

ARtículo 101. En las visitas ordinarias ... De toda visita de inspección deberá levantarse acta circunstanciada, en la cual se hará constar el desarrollo de la misma, las quejas o denuncias presentadas en contra de los titulares y demás servidores del órgano de que se trate... El acta levantada por el visitador será entregada al titular del órgano visitado y al secretario ejecutivo de disciplina a fin de que determine lo que corresponda y, en caso de responsabilidad, dé vista al Consejo de la Judicatura Federal para que proceda en los términos previstos en esta ley.

${ }^{37}$ Ley Federal de responsabilidad de los servidores públicos. http://www.diputados.gob.mx/LeyesBiblio/ref/lfrsp/LFRSP_ref11_09abr12.pdf 
el mal desempeño del servidor público, situación que prevalece en este tipo de procedimiento.

\section{LEY DE AMPARO, REGLAMENTARIA DE LOS ARTÍCULOS 103 Y 107 DE LA CONSTITUCIÓN POLÍTICA DE LOS ESTADOS UNIDOS MEXICANOS ${ }^{38}$}

\section{III.1. Antecedentes del Amparo mexicano}

Previo a abordar el tema directo de la ley de amparo es importante destacar que José María Ots Capdequi ha considerado que el juicio de residencia, por su carácter eminentemente casacionista, es el antecedente directo e inmediato del juicio de amparo. ${ }^{39}$ Sin embargo no comparto este criterio con base en los siguientes razonamientos:

$\mathrm{Al}$ efecto el doctor Javier Alvarado Planas refiere en lo que fue el debate para la supresión del juicio de residencia, que en el tema relativo a la naturaleza jurídico-político de la residencia, se planteó si el fallo debía contener el pronunciamiento sobre la responsabilidad civil o penal, o si el objetivo de la residencia era un juicio elevado, más político que legal, sobre la administración del residenciado, resolviéndose esa situación con lo establecido en el Código de Indias, el que mencionaba la posibilidad de investigar minuciosamente la conducta de la autoridad para su castigo, tendiendo a la reparación del daño causado al agraviado, cuya honra, libertad o interés haya sido afectada por el funcionario residenciado en ejercicio de su desempeño. ${ }^{40}$. No se soslaya que el juicio de residencia tenía un órgano de apelación, que en principio fue España, después pasó a la Audiencia de Indias y posteriormente al Consejo y Caudillerías, para terminar siendo revisadas en los distintos distritos, y que si bien pudiera considerarse esta apelación como el antecedente del recurso de casación, más cierto es que su origen era netamente político y por tanto la revisión consistía en la evaluación del funcionario sancionado, ya que era sobre la resolución que emitía el juez de residencia por motivo de su desempeño, mientras que en el juicio de amparo mexicano, es por conflictos entre civiles y la autoridad, por motivo de violación a sus derechos humanos y no por su desempeño en cargo público, pues

${ }^{38}$ Diario Oficial de la Federación, 2 de abril de 2013.

${ }^{39}$ Cfr. Por Barragán BarRagán, José, El juico de responsabilidad en la Constitución de 1824 (antecedente inmediato del amparo), México, UNAM, 1978, pág 12.

${ }^{40}$ Alvarado Planas, Javier, Control y responsabilidad en la España del XIX: El juicio de residencia del Gobernador General de Ultramar, Madrid, Dykinson, 2010, pág. 164. 
incluso la propia Constitución Política de los Estados Unidos Mexicanos, impide a la autoridad judicial de amparo, conocer de las resoluciones que sobre juicio político y declaración de procedencia se emitan. ${ }^{41}$

Es importante destacar que el juicio de amparo Mexicano tiene dos aspectos, uno que es el amparo indirecto ${ }^{42}$ que se presenta antes jueces federales, el cual corresponde a un verdadero juicio en el que se presenta demanda, se oye a los interesados (generalmente es la autoridad), se ofrecen y desahogan pruebas, se reciben alegatos y se dicta sentencia; este juicio tiene como finalidad que el juez proteja a los particulares de las violaciones a sus derechos humanos que se comentan en su contra por la autoridad ${ }^{43} \mathrm{El}$ juicio de amparo directo ${ }^{44}$ que es el revisor de las sentencias dictadas por los jueces procesales, sólo se revisan las actuaciones de la autoridad jurisdiccional de la que emana el acto, por tanto es indiscutible que se está en presencia de un verdadero recurso de casación, sin que se considere que el origen sea el juicio de residencia español. Al respecto Mariano Azuela Rivera ${ }^{45}$, citando a Emilio Rabasa menciona que el amparo mexicano tiene

${ }^{41}$ http://www.diputados.gob.mx/LeyesBiblio/pdf/1.pdf. Constitución Política de los Estados Unidos Mexicanos. Artículo 110. Podrán ser sujetos de juicio político los senadores y diputados al Congreso de la Unión, los ministros de la Suprema Corte de Justicia de la Nación,..... Las declaraciones y resoluciones de las Cámaras de Diputados y Senadores son inatacables.

${ }^{42}$ Diario Oficial de la Federación 02 de abril 2013. Ley Reglamentaria de los artículos 105 y 107 de la Constitución Política de los Estados Unidos Mexicanos. Artículo 107. El amparo indirecto procede: I. Contra normas generales... II. Contra actos u omisiones que provengan de autoridades distintas de los tribunales judiciales, administrativos o del trabajo; III. Contra actos, omisiones o resoluciones provenientes de un procedimiento administrativo seguido en forma de juicio,... IV. Contra actos de tribunales judiciales, administrativos, agrarios o del trabajo realizados fuera de juicio o después de concluido.... V. Contra actos en juicio cuyos efectos sean de imposible reparación... VI. Contra actos dentro o fuera de juicio que afecten a personas extrañas; VII. Contra las omisiones del Ministerio Público en la investigación de los delitos... VIII. Contra actos de autoridad que determinen inhibir o declinar la competencia o el conocimiento de un asunto.

${ }^{43}$ La Ley de amparo vigente, permite este amparo indirecto, en contra de los particulares, cuando los actos que desempeñen tengan características de autoridad, en las que creen, modifiquen o extingan derechos u obligaciones de los gobernados. En amparo directo, sigue siendo en contra de la resolución que emita la autoridad jurisdiccional, por tanto sigue siendo recurso de casación.

${ }^{44}$ Ídem. Artículo 170. El juicio de amparo directo procede: I. Contra sentencias definitivas, laudos y resoluciones que pongan fin al juicio, dictadas por tribunales judiciales, administrativos, agrarios o del trabajo, ya sea que la violación se cometa en ellos, o que cometida durante el procedimiento, afecte las defensas del quejoso trascendiendo al resultado del fallo....

${ }^{45}$ Azuela Rivera, Mariano. Texto de Amparo, México. Poder Judicial de la Federación, Suprema Corte de Justicia de la Nación, 2006, pág 12. 
categoría mixta: la de juicio de amparo y la de recurso. Al primero lo refiere como aquel procedimiento que tiene por efecto la restitución de alguna violación a los derechos humanos, siempre que no se funden en lo dispuesto por el artículo 14 de la Constitución Política de los Estados Unidos Mexicanos ${ }^{46}$, y el segundo tiene su origen en una aplicación indebida de la Ley por motivo de una resolución jurisdiccional, precisamente encuadrada como violación del artículo antes mencionado y cuya finalidad es que sea revisada esa sentencia en una instancia superior. No obstante lo anterior, es incuestionable que en la época colonia, el sistema jurídico-político mexicano tuvo la influencia del sistema Español, y aunque ese derecho estaba basado más en el respeto a los pueblos conquistados por razones de carácter religioso, fue recogido por las ordenanzas y cédulas de la Recopilación de Leyes de Indias, de 1681, sin que se acataran de manera estricta, pues los indígenas eran vejados por españoles, criollos y mestizo. ${ }^{47}$

Es incuestionable la influencia del derecho Español, especialmente de las siete partidas, en las instituciones judiciales, y en los procedimientos y sus recursos legales, sin embargo los investigadores aún no se ponen de acuerdo si estas constituyen propiamente un antecedente del juicio de amparo, pues la división está encaminada a dos corrientes: una que encuentra ciertas características de los procedimientos constitucionales en los antecedentes coloniales y otros que consideran que el juicio de amparo no aparece en la vida jurídica de la Nueva España sino hasta el México Independiente, gracias a las ideas de los juristas Manuel Crescencio Rejón y Mariano Otero.

Respecto de quienes consideran que el amparo mexicano tiene antecedentes anteriores al México Independiente, se encuentra Andrés Lira González, quien señala: "Quienes ignoraron o desdeñaron su pasado, cerraron los ojos ante lo más propio y operante en un presente que definian como novedad. En efecto, en la época colonia, hay una larga tradición que institucionaliza al amparo dentro de un sistema de derecho, no tan expreso formalmente como el constitucional mexicano, pero sin duda sí más vigente en la realidad. Es aquí, en la vigencia, en la costumbre, donde nace el empleo del término amparo para designar una institución que nuestros legisladores del siglo XIX recogieron, quizá in-

${ }^{46}$ Constitución Política de los Estados Unidos Mexicanos. Artículo 14. A ninguna ley se dará efecto retroactivo en perjuicio de persona alguna. Nadie podrá ser privado de la libertad o de sus propiedades, posesiones o derechos, sino mediante juicio seguido ante los tribunales previamente establecidos, en el que se cumplan las formalidades esenciales del procedimiento y conforme a las Leyes expedidas con anterioridad al hecho

${ }^{47}$ Espinoza Barragán, Manuel Bernardo, Juicio de amparo, México, Trillas, 2002, pág 11. 
conscientemente para incorporarla a su modernidad, cumpliendo con la idea o la exigencia de una constitución escrita. Ahora bien, no por ignorada la tradición es menos operante; además queda pendiente el grado de ignorancia efectiva. ¿No fueron REJÓN y OTERO educados en la lectura del derecho Neoespañol?, ¿Hasta qué punto eran conscientes del amparo como tradición y lo introdujeron en un nuevo sistema de derecho propio, más que imitado? ${ }^{48}$

Lo anterior tiene lógica, pues en Las siete partidas ya se recogía el término "amparamiento" desde la época medieval para referirse a la relación que se establecía entre personas desvalidas y desprotegidas y aquel señor que se comprometía a protegerlos. También se aludía con este vocablo al contrato en el que se hacían constar los derechos y obligaciones del protector y de los protegidos. Surgieron también las denominadas «cartas de amparos» para referir a las escrituras expedidas por el monarca, con la finalidad de otorgar especial protección a una persona, estipulándose las correspondientes sanciones a quien no la cumpliera. ${ }^{49}$. José Luis Soberanes Fernández y Faustino José Martínez Martínez, refieren que el panorama de las siete partidas, relativo al "amparo» o "amparamiento» no es suficiente para creer que sea el presente expreso del amparo mexicano, ya que no se encuentra en ellos la defensa de derechos y garantías propiamente, de la manera en que se consolidan en la actualidad, pues aquellas conservaban la concepción estamental del rey, además de que consideraban mecanismos distintos a lo que hoy es el amparo, como la alzada que no tenía por fin el análisis de las violaciones de derechos individuales ${ }^{50}$. Refieren que "no se puede afirmar por ende, la existencia de un precedente directo en las partidas. Eso no es posible porque nos movemos en contextos diferentes desde los puntos de vista posibles. Lo que sí estamos en condiciones de afirmar es que las partidas y su proyección americana, constituyen el antecedente indirecto del amparo, en cuanto a que introducen a la América hispánica en la tradición del derecho común y crean todo un cuerpo de mecanismos defensivos desde el punto de vista procesal, que tendrán extraordinario desarrollo en los modernos ordenamientos procesales.» ${ }^{51}$

${ }^{48}$ LiRa GonZÁlez, Andrés, El amparo colonial y el Juicio de amparo mexicano, México, Fondo de Cultura Económica, 979, pág 74.

49 Altamira y Crevea R. Diccionario castellano de palabras jurídicas y técnicas tomada de la legislación Indiana, México, UNAM, 1987, págs 17 y 18.

${ }^{50}$ Soberanes Fernández, José Luis, Martínez MarTínez, Faustino José, Apuntes para la historia del juicio de amparo, México, 2010, pág 73.

51 Ídem, pág. 72. 
En el México Independiente, la Constitución de Apatzingán en México (1814) cuando se incluye un capítulo denominado "garantías individuales", (derechos del hombre) y que tenían que ser respetados por el poder público, sin embargo no contenía un sistema para hacerlo efectivo, por tanto no se puede considerar el antecedente del juicio de amparo, pues como se ha dicho, éste tiene como finalidad hacer efectivo el respeto de esos derechos. Una vez consumada la Independencia se redacta la Constitución Federativa de 1824, cuyo objetivo principal fue poner orden en la política del estado mexicano, dejando en segundo plano las cuestiones relativas a los derechos del hombre, sin embargo sí se plasmó en este documento la facultad a la Corte Suprema de Justicia, para conocer de las infracciones de la Constitución y leyes generales. En 1836, se forma la ley fundamental con el nombre de Siete Leyes Constitucionales, en la que se crea el órgano político denominado Supremo Poder Conservador, el cual era encargado de defender la Constitucionalidad de las leyes. No es sino hasta el Proyecto de Constitución de Yucatán de 1840, cuando Manuel Crescencio Rejón, plasmó por primera vez durante este México Independiente, las bases de lo que hoy se conoce como el juicio de amparo, hay que recordar que en esa época éste estado pretendía separarse de la República Mexicana, por lo que elaboraron su propio proyecto de Constitución en el que se estimó que era necesario incluir aspectos de garantías individuales en favor de la población, creando un medio de control en dicho documento, al que denominaron amparo. Cuando la provincia de Yucatán regresó a seno de la República Mexicana, entregó esta obra para que se perfeccionara y se incorporará al régimen constitucional.

En las bases orgánicas de 1843, se suprimió el Supremo Poder Conservador y se le otorgó al Poder Judicial la facultad de revisar sentencias que dictaran los jueces inferiores en lo relativo asuntos civiles y penales, y al Congreso se facultó para que reprobara los decretos dados en las asambleas departamentales contrarios a la Constitución o a las leyes.

La Constitución de 1847, denominada Acta de Reforma, recoge las ideas de Crescencio Rejón y Mariano Otero, en cuyo artículo $25^{52}$ es-

\footnotetext{
${ }^{52} \mathrm{http}: / /$ www.ordenjuridico.gob.mx/Constitucion/1847.pdf Acta Constitutiva y de Reformas 1847. Artículo 25. Los tribunales de la Federación ampararán á cualquiera habitante de la república en el ejercicio y conservación de los derechos que le concedan esta Constitución y las leyes constitucionales, contra todo ataque de los poderes legislativo y ejecutivo, ya de la Federación, ya de los Estados; limitándose dichos tribunales a impartir su protección en el caso particular sobre que verse el proceso, sin hacer ninguna declaración general respecto de la ley o del acto que lo motivare.
} 
tablece el sistema de defensa de las garantías individuales (derechos humanos) dando lugar real y formalmente a lo que es el juicio de amparo mexicano.

Las Constituciones de 1857 en sus artículos 101 y 102, así como la de 1917 (actual) en sus artículos 105 y 107, establecieron un control de la constitucionalidad y de protección de los derechos humanos. Lo anterior robustece el criterio de que el amparo tiene su origen en México y que si bien es cierto tuvo influencia española, no menos cierto es que se consolida como garante de los derechos humanos, estableciendo mecanismos para hacerlos valer en la República Mexicana. Lo anterior es claro en cuanto a la influencia del derecho español en el amparo mexicano, más no, que el juicio de residencia sea precursor del juicio de amparo mexicano, en los términos en que ha quedado anotado en este documento.

\section{CONCLUSIONES}

El juicio de residencia, como he apuntado al inicio de este estudio, fue aquel procedimiento que se estableció con la finalidad de valorar y en su caso sancionar la actuación de los funcionarios que tuvieron cargos públicos, es decir tuvo como objetivo revisar el actuar político de los empleados del estado, mientras que el juicio de amparo en su faceta de casación, tiene como finalidad la protección de los derechos humanos de los particulares frente al estado; en este tipo de procedimientos se hace el análisis y valoración de la aplicación correcta de la ley para lograr el efectivo estado de derecho de los gobernados, mientras que en los juicios de responsabilidad de los servidores públicos se hace valoración de desempeño de los funcionarios de manera similar al juicio de residencia español, en los cuales, de encontrarlos responsables de su mal actuar, se les destituye, inhabilita y en ocasiones hasta sanciona económicamente. 